\title{
FiguRAÇõES DE CORPO NO ESPONTÂNEO DO FOTOJORNALISMO DIGITAL: A NÃO-POSE E A DESFIGURAÇÃo
}

\author{
Alene Lins, Madalena Oliveira \& Luís António Santos
}

\begin{abstract}
Resumo
Este artigo analisa as alterações tecnológicas que modificaram o espontâneo do fotojornalismo. Antes, o espontâneo era resultado da técnica e perícia do fotógrafo. Atualmente, graças a uma espécie de "agilidade" das câmaras fotográficas, ele tornou-se uma prática possível a qualquer foto-repórter. As fotografias sequenciais tornam o corpo do sujeito retratado um elemento manipulável do processo editorial. Em figurações que privilegiam gestos não concretizados e desfigurações, algumas imagens publicadas na imprensa alteram simbolicamente a representação social do retratado. $O$ estudo apresentado neste artigo também aponta para o uso de uma estética do grotesco presente nas expressões, nos gestos e postura do sujeito fotografado e para um discurso do espontâneo como um regime de poder exercido pela imprensa.
\end{abstract}

PaLAVRas-chave

Espontâneo no fotojornalismo; não-pose; imagem social; estética do grotesco

\begin{abstract}
This article analyses the technological changes that have modified the snapshot in photojournalism. Formerly, snapshot was a result of the technique and expertise of the photographer. Today, due to a kind of "agility" of the cameras, it has become a possible practice for any photoreporter. Sequential photographs turn the portrayed subject's body into a pliant element of the editorial process. In figurations that privilege unfulfilled gestures and disfigurements, some images published by the press symbolically alter the social representation of the person portrayed. The study described within this paper also points to the use of an aesthetic of the grotesque, present in the expressions, gestures and posture of the subject photographed and to a discourse of the snapshot as a regime of power exerted by the press.
\end{abstract}

KeYwORDS

Snapshot in photojournalism; non-pose; social image; aesthetics of the grotesque

\section{FOCAR NO ESPONTÂNEO}

A foto única, o momento decisivo ou o congelamento do instante, defendido por Erich Salomon, na década de 1920 e por Henri Cartier-Bresson, na década de 1950, deram origem ao espontâneo no fotojornalismo (Freund, 1983; Sousa, 2001). Uma tradição dos géneros factuais, que não aceita a simulação ou a encenação, e que retrata o sujeito quase sempre em ação durante um acontecimento. No período em que o espontâneo surgiu, cabia ao fotógrafo dominar uma série de comandos manuais e com a 
sensibilidade do olhar, coordenar o acionamento do obturador no momento exato, para congelar uma imagem síntese (Sousa, 2001; Freund, 1983; Machado, 1984). Alterações na tecnologia de captação das fotografias, que começaram em 1970 e se acentuaram na década de 2000, permitiram que todo e qualquer fotógrafo produza séries de fotografias contínuas automáticas. São, por isso, talvez menos artísticas e mais tecnológicas as condições atuais que sustentam a chamada técnica do espontâneo, que transportam para a fase de seleção e edição, mais do que de captação, a construção social da imagem dos sujeitos representados.

A captação fracionada de cada movimento de corpo do sujeito retratado fez surgir um fenómeno cada vez mais presente nas editorias de política dos jornais, revistas e sites: figurações fora do que culturalmente compreendemos como normal. Se "fotografar é apropriar-se da coisa fotografada", como afirma Susan Sontag (2004, p. 8), o corpo fotografado é então um objeto manipulável nos processos de escolha editorial do fotojornalismo. Um editor, ao escolher uma pose, uma não-pose ou uma desfiguração de um retratado, transforma tal figuração em parte da notícia.

Este artigo foca-se nas alterações tecnológicas que permitiram a captação sequencial do corpo. Entendemos que é das novas condições técnicas da fotografia que surgiu o espontâneo da não-pose, do gesto não concretizado e da desfiguração. A abordagem desenvolvida neste trabalho é resultado de uma revisão de literatura, que procura interpretar a estética deste espontâneo na sua associação com o estilo grotesco, tomando-o como conceito de Bakhtin: "o exagero, o hiperbolismo, a profusão, o excesso são, segundo opinião geral, os sinais característicos mais marcantes do estilo grotesco" (Bakhtin, 1987, p. 265).

Através de análise crítica da literatura revisada, empreendemos o método dedutivo para compreender os processos históricos que envolvem o surgimento do espontâneo e demonstrar que atualmente ele não se justifica enquanto técnica. O espontâneo tornou-se, na verdade, uma prática tecnológica. Já o nosso percurso teórico na associação do espontâneo ao estilo grotesco foi estabelecido em diálogos com a Antropologia, a Psicologia, a Sociologia e a Estética, sobre figurações do corpo enquanto informação, princípio básico do fotojornalismo.

\section{O ESPONTÂNEO NO FOTOJORNALISMO, DA TÉCNICA À PRÁTICA}

No início da fotografia documental - ainda a relativa distância do efeito de naturalização do universo de imagens de que fala Anabela Gradim (2007, p. 190) - a pose era uma necessidade por questões técnicas, mas duas coberturas de guerra contribuíram para estabelecer a diferença entre o fotodocumentalismo posado e outro mais realístico. As duas guerras, cujas coberturas fotográficas padeceram das mesmas limitações tecnológicas, obtiveram resultados conceptuais divergentes. A cobertura encomendada da Guerra da Crimeia, ao fotógrafo Roger Fenton, em 1855, resultou em 360 imagens. São retratos de oficiais, fotos de paisagens do acampamento militar, dos soldados em momentos de descanso, montados em cavalos, exibindo armas, sempre muito dignos 
nas suas poses'. Enviado pela Coroa Britânica, Fenton tinha como objetivo para a cobertura produzir imagens que dessem alento aos familiares dos soldados. Com um tempo de exposição que variava entre 10 e 15 segundos, ele conseguiu um eficiente trabalho de direção de fotografia, pois muitas das suas fotos parecem ações em andamento. As imagens foram publicadas e causaram forte impacto na sociedade europeia. Seis anos depois, em 1861, Mathew Brady, Alexander Gardner e Timothy O'Sullivan, no registo da guerra civil americana, fizeram o primeiro trabalho de fotodocumentalismo realístico, com resultados bem distintos da primeira cobertura. Eram cenas dos corpos dos soldados alinhados, muitos mutilados, casas destruídas, situações de horror e violência nas trincheiras, que só uma guerra é capaz de provocar. Com estas duas comparações, o fotodocumentalismo e, posteriormente, o fotojornalismo acabaram por criar uma certa rejeição à pose em situações factuais (Freund, 1983; Sousa, 2002).

Jorge Pedro Sousa fala de um início do fotojornalismo fundamentado em géneros realistas, que mais tarde saíram do reino da verdade para um reino do credível. A própria criação do fotodocumentalismo fortalece a discussão de realismo, frente aos debates teóricos sobre o ponto de vista, a perspetiva e outras formas de manipulação, antes mesmo da edição. Mas, de alguma forma, ao fotojornalismo coube uma dimensão de construção social da realidade, em consonância com a mesma dimensão que recebe o jornalismo (Sousa, 1998). E coube ainda a responsabilidade de produzir um acervo de imagens históricas, que compõem uma parte da memória visual da nossa época, cuja importância civilizatória é analisada por Umberto Eco, na obra La Guerre du Faux. Com efeito, o semiólogo italiano cita uma série de imagens famosas, entre elas a de Che Guevara martirizado, estendido sobre uma cama de campanha numa caserna, ou o miliciano assassinado, registado por Robert Capa, ou o vietnamita fotografado pouco antes da sua execução. "Cada uma destas imagens", que resumem as vicissitudes da humanidade após a invenção da fotografia, diz Umberto Eco, "tornou-se mito e condensou uma série de discursos. Ultrapassou as circunstâncias individuais que a produziram (...) e exprime conceitos" (Eco, 1985, p. 212). Continua o autor, reconhecendo que cada uma dessas fotos "é única, mas ao mesmo tempo reenvia para outras imagens que a precederam ou que a seguiram por imitação" (Eco, 1985, pp. 212-213). Na nossa civilização, acostumada a pensar por imagens, fotos dessa natureza funcionaram como referência, independentemente do facto de serem uma simulação, de existir uma pose, de ser algo encenado, segundo Eco. Pouco importa se foi resultado de um fotógrafo profissional que calculou o momento, a luz, a composição. A partir do instante em que uma fotografia com essa força imagética é publicada, e pelo facto de ser fotojornalismo, diz o semiólogo italiano que a sua "marcha comunicativa começou: mais uma vez o político e o privado foram atravessados pelas tramas do simbólico, que, como sempre, provaram que ele era o produtor da realidade" (1985, p. 213).

A fotografia começou a ser usada em publicações jornalísticas a partir de 1885, em revistas e periódicos mensais. Para Jorge Pedro Sousa, as publicações que privilegiaram a fotografia marcaram uma mudança conceptual na época, pois as imagens deixaram de

\footnotetext{
'Retirado de http://www.allworldwars.com/Crimean-War-Photographs-by-Roger-Fenton-1855.html
} 
ser secundarizadas como ilustrações de textos, para se tornarem uma categoria informativa: fotojornalismo, informação através da fotografia, um veículo de observação, de análise e interpretação (Sousa, 2002).

A pose, enquanto figuração do fotojornalismo, era muito utilizada, paradoxalmente até mesmo para dar a impressão de algo não encenado, pois as personagens podiam parecer não perceber a câmara, mas precisavam de ficar paradas para garantir uma boa imagem. O retrato já foi um dos géneros fotográficos mais publicados (Freund, 1983). Nos seus diversos géneros, a fotografia de imprensa divulgava tanto o retrato de uma única personagem como os retratos coletivos, onde novas culturas passaram a ser vistas:

a introdução da fotografia na imprensa é um fenómeno de fundamental importância. Muda a visão das massas. Até então, o homem comum só podia visualizar os acontecimentos ao seu redor, em sua rua, em seu povoado. Com a fotografia abre-se uma janela para o mundo. Os rostos dos personagens públicos, os acontecimentos que ocorrem pelo país e além das fronteiras, tornam-se familiares. Ao alargar a visão, o mundo se encoIhe. (Freund, 1983, p. 96)

No início, por causa das impossibilidades técnicas, com equipamentos grandes e pesados, flashes que estouravam e cheiravam a enxofre, o fotojornalismo atraiu profissionais mais por características físicas do que por capacidade técnica-sensorial. Apenas nos anos 1920, com uma efervescente mudança cultural, social e científica na Alemanha, associada à chegada de câmaras menores, apareceu uma geração de novos fotógrafos, cujo conceito de autoria permitiu um desenvolvimento técnico e estético no fotojornalismo. Os fotógrafos desse período, diferentes da geração que os precedeu, tinham sido educados no portar-se, no vestir-se e falavam diversas línguas. Foi neste meio que surgiu o doktor Erich Salomon, advogado, que durante cinco anos atuou como foto-repórter (1928-1933).

Salomon fotografava no início com uma câmara Ermanox, pequena, compacta, com objetiva muito clara, que permitia fotografar em ambientes internos sem uso de flash, depois com uma câmara Leica, com objetivas intercambiáveis e ainda mais claras, e filmes de 36 poses, que permitiam maior autonomia. Ele conseguia destacar-se com estes equipamentos a que se associava uma extraordinária perícia do fotógrafo. Salomon produziu fotos de pessoas influentes em situações inusitadas, com a câmara desapercebida. Com isso, ele foi o criador de um estilo de registo, principalmente de pessoas influentes. O estilo adotado por Salomon ficou conhecido como candid photographies e passou a ser um género génese de outros géneros, a ponto de se constituir como um discurso específico do fotojornalismo - retratar o espontâneo, uma intrínseca relação entre desarmar a pose do retratado e evidenciar o realismo do acontecimento, reforçar o caráter de uma fotografia comprometida com a verdade (Freund, 1983; Sousa, 2002). Ali nascia o fotojornalismo moderno, onde a informação se sobrepõe à qualidade técnica da imagem. As suas fotos foram publicadas em jornais importantes do mundo ocidental. 
Salomon foi, aliás, o primeiro a usar o termo "foto única" na fotografia de imprensa (Freund, 1983, p. 105).

Mais tarde, em 1952, o fotógrafo francês Henri Cartier-Bresson publicou o livro Images a la Sauvette, editado em inglês com o título The decisive moment, sobre a foto do instante em que algo importante acontece, fortalecendo a ideia da foto única. Cartier-Bresson era um dos sócios da Agência de Fotos Magnum, criada em 1947, num sistema de colaboração entre muitos fotógrafos talentosos, cujo objetivo inicial era produzir fotografias de autor, em missões jornalísticas e documentalistas pelo mundo todo ${ }^{2}$. $\mathrm{O}$ seu livro conceptualiza o instante decisivo como a captação de um momento único, quando o fotógrafo consegue congregar todo o significado de um facto numa imagem. O momento único é então uma ação, um gesto, uma expressão do fotografado, e pode ser ainda uma combinação de elementos ao fundo, que, sem suplantarem o motivo principal, na altura ajudam a compreender o que está em causa no acontecimento (Sousa, 2002). Na sua vida profissional, Cartier-Bresson publicou em veículos jornalísticos de renome, fez diversas exposições e recebeu um número extraordinário de prémios. Foi, reconhecidamente, um dos mestres do espontâneo³.

Salomon e Bresson, pelo resultado das suas fotografias, pelo prestígio e reconhecimento histórico enquanto profissionais de talento, e por sustentarem as suas práticas na técnica que dominavam, fortaleceram o discurso de uma fotografia de imprensa sem pose. Salomon e Bresson tinham total controlo da mecânica e da ótica da câmara, dos efeitos da luz e uma sensibilidade do olhar. Por estes motivos são os dois mais fortes contributos para os géneros do espontâneo no fotojornalismo. Mas fica muito evidente com os dois que a tecnologia analógica exigia perícia.

O operator, aquele que opera a câmara, segundo Barthes (1984), precisava de coordenar muitas tarefas nos tempos de equipamentos de controlo total manual. Ele fazia cálculos para quantificar a luz e em qual velocidade/tempo essa luz deveria permanecer sensibilizando o filme, observar qual a profundidade de campo a partir da abertura usada e a distância do objeto, escolher a sua melhor posição e ângulo para enquadrar, selecionar o recorte, aguardar o melhor momento no visor da câmara, operar o anel do foco, ajustando à medida em que o sujeito a ser retratado se movia, e, finalmente, apertar o botão disparador ${ }^{4}$. Se fosse necessária uma sequência de fotos, o fotógrafo da câmara analógica precisava de acionar manualmente o comando de passar o filme adiante para sensibilizar um novo fotograma. Não era possível fazer dezenas de fotos por segundo. Talvez duas ou três fps (fotos por segundo), para um fotógrafo muito competente. $\mathrm{Na}$ imprensa, o foto-repórter precisava também de ter um poder de síntese do acontecimento, a ponto de produzir poucas imagens que gerassem significado ao ocorrido.

Bresson e Salomon demonstraram que fotografias jornalísticas são artefactos de génese pessoal, social, cultural, ideológica e tecnológica, pois cada foto-repórter carrega

\footnotetext{
${ }^{2}$ Retirado de https://www.magnumphotos.com/about\%2omagnum/overview/

3 Retirado de https://www.magnumphotos.com/photographer/henri-cartier-bresson/

4 Observações empíricas, advindas da experiência desta pesquisadora, que atuou durante 10 anos como fotógrafa, no período analógico, primeiro com Nikon FM10 e Pentax K1000, de total controlo manual, depois com Canon EOS 50, com motor drive, eletrónica (1992 a 2002).
} 
em si a sua capacidade, a sua perceção, o seu senso estético, o seu profissionalismo, a sua atuação ética, além da sua competência para lidar com a tecnologia (Sousa, 1998). No recorte, há um processo de escolhas, desde as lentes, a perspetiva ou ponto de vista, e tudo interfere no resultado. Para além dessa produção, na veiculação da fotografia de imprensa há outro profissional, o editor, que escolhe qual imagem será publicada e que destaque ela vai ter no conjunto da publicação.

O discurso do espontâneo sedimentou os géneros do factual, de cobertura in loco, espaço editorial onde a pose e a encenação eram menosprezadas. Géneros como spot news, general news, features, desporto, entre outros, carregam características de instantâneos (fotos do instante em que os factos aconteceram), possuem fundamentos no espontâneo (não houve simulação, encenação). Uma personalidade, seja ela um político, um artista, um atleta, no factual, é, quase sempre, retratada em figuração que expresse alguma ação em andamento, sem elaboração evidente (Sousa, 1998, 2002).

Enquanto o discurso do espontâneo se fortalecia, as alterações tecnológicas na captação de uma fotografia de imprensa começaram a ocorrer, ainda que lentamente, seis anos após a publicação do livro de Henri Cartier-Bresson sobre o momento decisivo. Em 1958 a Leica lançou a MP2, uma câmara experimental, com motor elétrico, que teve no primeiro lote apenas 12 unidades e no segundo lote, em 1959, 15 unidades. Eram as primeiras do mercado a dispensarem o acionamento manual do filme. Elas avançavam a película automaticamente, disparo após disparo. Essas câmaras nunca chegaram a ser fabricadas em larga escala5. Foram câmaras tão revolucionárias que têm grande valor histórico e portanto, também de mercado, para colecionadores. Em 2010, vendida em leilão, uma dessas unidades atingiu o valor de 402 mil euros (Máquina fotográfica Leica vendida por valor recorde, 2010).

Mas outras marcas também lançaram motores para adiantar e rebobinar o filme a partir dos anos 1960. Eram motores externos à câmara, acoplados. Câmaras com motor drive inseridos foram as novidades da década de 1970. Uma das mais importantes foi a linha Nikon F, que conseguia sete $f p s^{6}$. O motor drive significava rapidez, economizava o tempo do fotógrafo em ajustes. Neste período teve início uma alteração significativa no espontâneo, pois havia a possibilidade de 36 fotos de um sujeito, em sequência, em poucos segundos. Os fotógrafos profissionais costumavam usar rolos de filmes com mais fotogramas, num sistema artesanal, mas que ainda assim era limitado. E havia o processo de troca de cartucho, onde o filme era totalmente rebobinado para que a película fosse protegida da luz. Além disso havia o encaixe manual de um outro cartucho de filme na câmara, que levava alguns minutos. O profissional, sabendo disso, utilizava um filme com certo cuidado, para não ter o risco de ficar sem fotogramas disponíveis num momento importante da cobertura?

\footnotetext{
${ }^{5}$ Esta informação pode ser confirmada no site da Leica, disponível em LeicaPhilia.com

${ }^{6}$ Retirado de http://imaging.nikon.com/history/chronicle/rhnco4f2-e/index.htm

7 Esta pesquisadora atuou como fotojornalista freelancer de 1992 a 2002, em coberturas para pequenos veículos e assessorias. Observações da prática no período.
} 
A década de 1990 trouxe alterações ao modo de produzir, armazenar e divulgar fotografias e essa realidade também alterou a técnica do espontâneo. Em 1992, a empresa do Vale do Silício SanDisc iniciou pesquisas em consórcio com Canon, Kodak e outras empresas fabricantes de equipamentos fotográficos, e em 1994, lançou o compact flash card. Em 1997, a tecnologia digital dos sensores e cartões de memória tornou-se popular, quando a empresa SanDisc produziu um milhão desses cartões naquele ano ${ }^{8}$. Com isso, as câmaras digitais foram aperfeiçoadas, com custos mais reduzidos e mais acessíveis, já no início da década de 2000. É também por isso que, de acordo com Sílvia Pinto e Moisés de Lemos Martins, "na época contemporânea, as fotografias transformaram-se na experiência visual por excelência" (2017, p. 262).

Um compact flash card possibilita gravar 100, 200 ou mais fotos de qualidade de visualização e impressão, de um único evento. Assim, a última barreira dos processos manuais foi extinta. Além disso, as máquinas fotográficas digitais permitem registos contínuos do obturador, por possuírem auto regulagens de foco e abertura. Basta que um fotógrafo acompanhe continuamente um sujeito ao falar e gesticular, e ele será registado em diversas fotografias em sequência. Diante do exposto fica claro que o espontâneo não depende mais da perícia do fotógrafo. Mas continua sendo um discurso do fotojornalismo, principalmente quando um sujeito tem a sua foto publicada, cuja figuração de corpo tem significados fora do campo da normalidade do que, culturalmente, associamos à imagem social do retratado.

\section{O GESTO NÃO CONCRETIZADO, A NÃO-POSE E A DESFIGURAÇÃo}

O espontâneo é a fotografia dos disparos desavisados que geram congelamento arbitrário de um momento. Geram figurações do corpo para as quais o fotografado parece não ter sido previamente preparado, onde, aparentemente, não houve encenação. Não houve uma atitude do sujeito diretamente ligada à sua figuração, antes da produção da fotografia. É o congelamento de um gesto natural, de uma expressão desarmada. Um espontâneo é sempre a ideia de uma não-pose, uma comunicação tão ou mais eficiente do que a pose, quando se pensa na decodificação da mensagem, pela associação cultural que se faz à pose. Afinal se não é uma pose, se é mais natural, se não houve encenação, entra-se na mítica da realidade, do simbólico fotográfico. Sem a pose subentende-se que o sujeito não tem máscara.

$\mathrm{Na}$ cobertura foto-jornalística de entrevistas é muito comum um sujeito em situação de não-pose, pois ela é resultado constante quando uma pessoa é fotografada ao falar e gesticular. Não há controlo do seu gestual ou das suas expressões, pois a fala requer uso de musculatura e as linhas de expressão do rosto acompanham a linguagem. Em velocidades muito altas e em disparos sequenciais, o obturador vai registar todas as expressões e gestos, ausências e presenças, que nem mesmo o olho humano consegue perceber em pormenores, concorrendo assim para uma espécie de "virtualização ótica" - uma expressão que Maria Teresa Cruz retoma de Friedrich Kittler numa passagem de um artigo em que se refere às imagens técnicas modernas (Cruz, 2007, p. 30).

\footnotetext{
${ }^{8}$ Retirado de https://www.sandisk.com/about/company/history
} 
Mesmo quando era ainda analógica, a câmara possibilitava ver o que o olho não via, como as quatro patas de um cavalo "suspensas" no ar, num momento sincrónico, que os experimentos de Eadweard Muybridge revelaram em 1887 (Machado, 1984, p. 50). Muybridge utilizou 12 câmaras, com os disparadores operando sequencialmente, através da técnica da chronophotography (Fabris, 2004). Ele deixou um acervo de mais de 20 mil imagens, com os seus estudos de cavalos e nus masculino e feminino, só sobre o movimento dos corpos. Os seus trabalhos, revelando o que o olho não via, relacionando tempo e movimento, inspiraram estudos de Rodin e de Degas, entre outros artistas, e deram origem ao termo instantâneo, na fotografia, segundo Fabris (2004). O certo é que a chronophotography possibilitou a Walter Benjamim, anos depois, teorizar sobre o inconsciente ótico e de como ver, através da fotografia, o que não percebemos a olho nu, nos possibilita novas descobertas, nos dá uma nova noção do mundo e entra em campos do imaginário.

Percebemos, em geral, o movimento de um homem que caminha, ainda que em grandes traços, mas nada percebemos de sua atitude na exata fração de segundo em que ele dá um passo. A fotografia nos mostra essa atitude, através de seus recursos auxiliares: câmara lenta, ampliação. Só a fotografia revela esse inconsciente ótico, como só a psicanálise revela o inconsciente pulsional. (Benjamin, 1987, p. 94)

Hoje existem câmaras que conseguem captar 10, 20, 25 mil fps 9 , que revelam quadro a quadro, o voo de um beija-flor ou como uma gota de chuva se espalha ao cair no chão. Mas bastam 60 fps de imagens sequenciais, para que o nosso olho perceba diversos movimentos que eram impercetíveis sem a câmara. Dessa forma, o inconsciente ótico revela-se cada vez mais.

No fotojornalismo, quando personalidades são acompanhadas por diversas câmaras, operadas por fotógrafos experientes, durante um discurso, os disparos sequenciais vão apresentar várias imagens de gestos não concretizados. Registados na fotografia, para Barthes, estes gestos não concretizados representam algo de singular. Escreve o autor: "o que funda a natureza da fotografia é a pose" (Barthes, 1984, p. 117). Para Barthes, pouco importa a duração física de uma pose, pois a pose não é uma atitude do alvo, não é o facto de o sujeito parar e se colocar em determinada posição, mas o facto de ele ter sido fotografado, e na fotografia a sua imagem está paralisada no tempo, há a imobilidade do sujeito fotografado, independentemente de ter sido intencional ou não. Para o semiólogo, todo o sujeito fotografado está em pose, pois a fotografia capta um movimento e paralisa-o. Mesmo que na realidade o sujeito não tenha demorado em tal posição, não tenha tentado construir sentido algum com ela, a fotografia dele, em tal posição, vai gerar sentido: as poses são fabricadas pela fotografia.

Um exemplo de um gesto não concretizado, resultado do inconsciente ótico, foi publicado em 1961, e interferiu na vida política do então presidente do Brasil, Jânio

\footnotetext{
${ }_{9}$ Retirado de https://www.phantomhighspeed.com/Products/Ultrahigh-Speed-Cameras
} 
Quadros. Após um estampido seguido de tumulto, ao virar-se para ver o que acontecia atrás de si, Jânio foi congelado com uma figuração inusitada: as suas pernas estavam enviesadas, parecem estar em sentidos opostos na imagem (Figura 1). A foto foi publicada no Jornal do Brasil. Com o sugestivo título de "Qual o rumo?", a imagem ganhou o prémio Esso na categoria Fotografia em $1962^{10}$. Segundo a historiadora Ana Maria Mauad (2008), Jânio ficou para sempre associado a tal figuração, enrolado nas suas próprias pernas, num desequilíbrio que sugere iminência de queda. Para a autora, a imagem demonstra uma ambiguidade física que também marcou a vida política da personagem, e sintetizava um momento do país. Meses depois, Jânio Quadros renunciou. O fotógrafo Erno Schneider, autor da fotografia, em entrevista à historiadora, relatou que foi uma única foto, um flagrante (Mauad, 2008).

A fotografia de Jânio Quadros retrata um momento em que um ser humano não consegue manter-se em pé por muito tempo, pois é um movimento involuntário, puro reflexo, que acontece em frações de segundos. Enquanto imagem, polissémica por natureza, é certo que uma fotografia suscita incontáveis interpretações, mas as figurações de corpo e rosto, na cultura ocidental, independentemente do facto a que estejam vinculadas, possuem os seus próprios significados, intrínsecos. Os significados do corpo, em algumas notícias, têm valores bem diversos do valor-notícia do facto, e a notícia associada à imagem de Jânio é um destes exemplos. O facto era um encontro entre o então Presidente do Brasil e o então Presidente da Argentina Arturo Frondizi. A notícia não era o susto de Jânio no tumulto, pois isso só se soube no relato que o fotógrafo deu à historiadora. Mas a imagem de Jânio, naquela situação anormal, foi transformada num facto fotográfico, e foi ainda a figuração de corpo imortalizada na história política da personalidade do ex-Presidente. O mecanismo automático que captou o inconsciente ótico de um corpo em movimento foi o responsável pela fotografia. Aquela imagem foi, no entanto, percebida pela população brasileira como sua pose, enviesada, na visão barthesiana.

Giddens contextualiza uma série de pesquisas com povos diferentes e suas expressões faciais, posturas e gestos, e afirma que "tal como sucede com expressões faciais, os gestos e a postura corporal são constantemente utilizados para completar expressões verbais e também transmitir significados sem que nada seja dito" (Giddens, 2008, p. 85). Assim, podemos concluir que uma não-pose é também facilmente reconhecível e que, enquanto imagem, transmite significados mesmo que não haja palavras que as contemplem. As pernas desarranjadas, a postura disforme e a ligação à ideia do desequilíbrio são inevitáveis. Pois se nas experiências dos nossos corpos, relacionamos as experiências do corpo do outro, sabemos que corpos não se mantêm em pé quando as pernas estão enviesadas. Como imagem-mito do fotojornalismo, após a publicação no Jornal do Brasil, esta fotografia de Jânio iniciou a sua marcha comunicativa (Eco, 1985, p. 212), já que tal figuração marcou para sempre a história do político.

\footnotetext{
${ }^{10}$ Retirado de http://www.premioexxonmobil.com.br/site/premio_principal/index.aspx?year=1962
} 


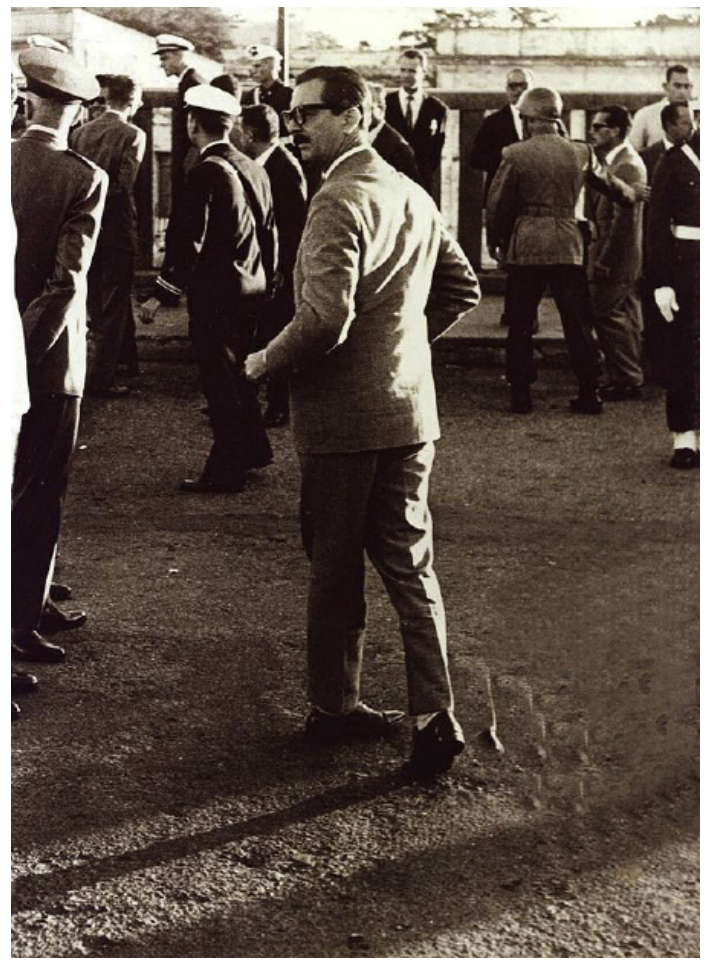

Figura 1: Qual o rumo? (fotografia de Jânio Quadros), Erno Schneider, 1961

Um outro exemplo de fotografia polémica, cujo gesto não concretizado se tornou um facto, para além do facto noticiado, foi vivenciado pelo Presidente americano Donald Trump e o ministro canadense Justin Trudeau (Figura 2). Logo após a posse de Trump, no dia 13 de fevereiro de 2017, aconteceu o primeiro encontro oficial entre eles. Numa das fotografias, Trudeau pareceu titubear para apertar a mão de Trump. A notícia do primeiro encontro oficial entre os dois chefes de nações foi reduzida por alguns tablóides ao significado do rosto titubeante do ministro do Canadá. A cena foi reproduzida incansavelmente, tornando-se meme". A repercussão da cena nas redes sociais converteu-se em notícia em revistas de larga difusão, como a Visão, em Portugal, e a Veja, no Brasil, e também nas notícias de televisão. Mas é possível perceber no vídeo do site do The Guardian $^{12}$ que Trudeau não tinha visto a mão estendida de Trump; ele olhava para os fotógrafos, enquanto o Presidente americano antecipava, por segundos, a mão estendida. Trudeau fez a expressão que parece ser de dúvida, direcionado aos fotógrafos, como se questionasse se eles estariam prontos para registar a fotografia oficial. Essa assimetria nos movimentos dos dois políticos gerou uma notícia falsa, um tipo de notícia que hoje se reconhece ser composta e manipulada para se assemelhar ao jornalismo credível e atrair a máxima atenção do público (Hunt, 2016). Em boa medida, as chamadas fake news são amplamente alimentadas por imagens interpretadas de forma equivocada. É

\footnotetext{
"Meme, do grego imitação; da biologia, replicação; um termo utilizado quando há recriação excessiva, coletiva e paródica de imagens (fixa ou cinética) e textos, por usuários de redes sociais na internet e nos smartphones (Horta, 2015).

${ }^{12}$ O vídeo intitulado “Donald Trump's strange handshake style and how Justin Trudeau beat it", pode ser visto em https:// www.theguardian.com/us-news/video/2017/feb/14/donald-trumps-strange-handshake-style-and-how-justin-trudeau-beat-it-video-explainer
} 
que, embora como refere Tito Cardoso e Cunha, a ação política exista hoje "muito essencialmente pela palavra, pelo discurso" (2009, p. 19), os gestos não concretizados e as figurações geradas por eles e captadas por uma câmara têm cada vez mais impacto na perceção construída da atuação dos políticos.
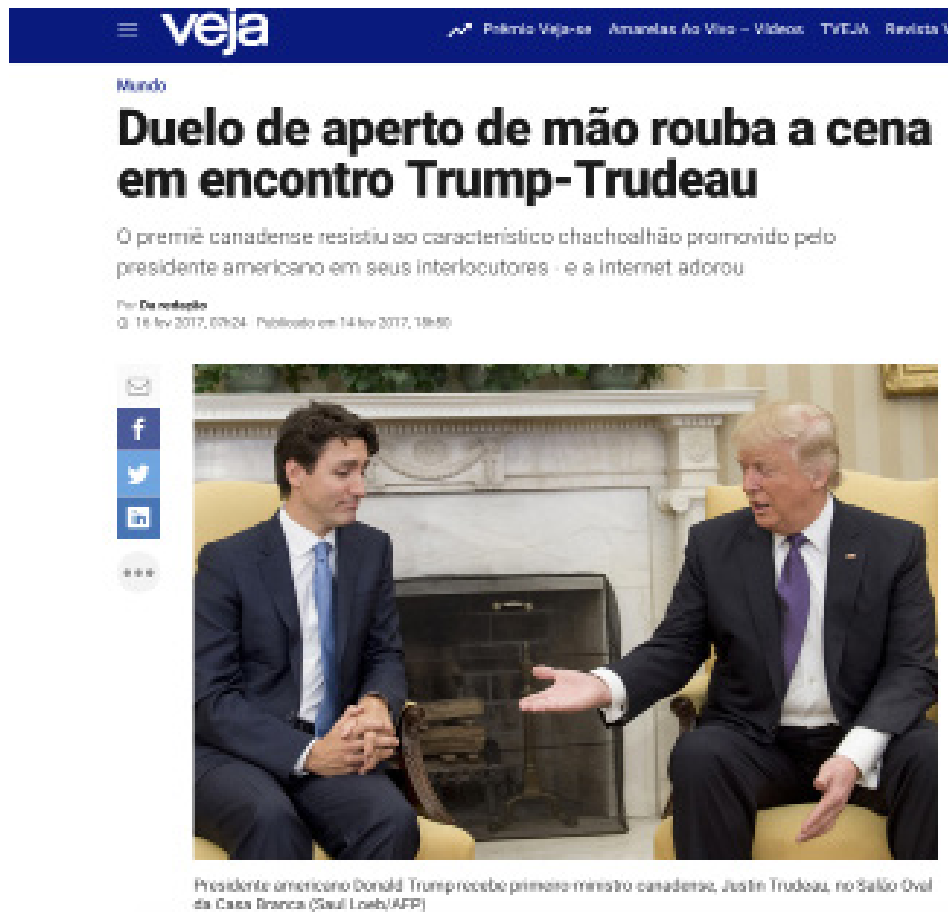

Figura 2: "Presidente americano Donald Trump recebe primeiro-ministro canadense, Justin Trudeau no Salão Oval da Casa Branca (Saul Loeb, AFP)"

Fonte: Duelo de aperto de mão rouba a cena em encontro Trump-Trudeau (2017); http://veja.abril. com.br/blog/headlines/ duelo-de-aperto-de-maos-rouba-a-cena-em-encontro-trump-trudeau/

O leitor de um veículo de imprensa percebe, interpreta, analisa, avalia e julga, não só o texto da notícia, mas também a fotografia que a acompanha, as expressões e figurações e dessa forma constrói significados sobre a personalidade do retratado. Destarte, neste artigo, vamos considerar que toda e qualquer figuração de corpo, em pose e em não-pose pode ter sentido para o leitor, pois o sujeito retratado esteve lá, gerou com o seu corpo algum sentido.

É importante diferenciar ainda a não-pose em duas categorias: normal e desfiguração. Os disparos desavisados atuam como a antítese da pose. Se a pose está associada a poder e status, por toda a carga cultural dos catálogos da pintura e da fotografia, sedimentados pelo hábito de retratar homens poderosos da aristocracia e da burguesia (Barrocas, 2014), a não-pose, ao contrário, coloca a imagem social do retratado em risco.

Arlindo Machado conclui que "ninguém gosta de ser surpreendido por um instantâneo, pois a imagem que ele nos dá sempre trai a ideia que nós fazemos de nós mesmos e que queremos passar adiante" (Machado, 1984, p. 51). Descendente direta de uma tradição pictórica aristocrática, de quem é também um resquício ideológico, a pose nem sempre "se deixa compatibilizar com as facilidades democráticas da câmara fotográfica: 
ela impõe, antes, uma certa sublimação do motivo e uma espécie de 'seleção natural' dos referentes" (Machado, 1984, p. 58). Os instantâneos não garantem que vamos sair bem na fotografia e isso também gera desconforto. Isso pode ser observado quando estamos em grupo e uma pessoa resolve fazer um registo fotográfico daquele instante. É notório que as pessoas se ajeitam, alinham os seus cabelos, as suas roupas, mudam as suas expressões com sorrisos, pois o instantâneo é um registo do instante, mas não necessariamente é uma não-pose. Um instantâneo nem sempre é um espontâneo. Barthes constata que, sempre que nos sentimos olhados por uma objetiva, tudo muda. "Eu me ponho a 'posar', fabrico-me instantaneamente um outro corpo, metamorfoseio-me antecipadamente em imagem" (Barthes, 1984, p. 22).

O desconforto de posar é grande, mas pior que isso é o desconforto mental de antecipar uma imagem distorcida, diferente da imagem que queremos divulgar e imortalizar. Há uma relação psicológica e antropológica entre o nosso corpo e a imagem corporal que queremos divulgar. O médico psiquiatra austríaco Paul Ferdinand Schilder publicou em 1935, o livro The image and appearance of the human body, onde apresentou o conceito de imagem corporal social. Para Schilder, "a imagem do corpo humano significa a figuração de nosso próprio corpo que formamos em nossa mente, isto é, a maneira como o corpo aparece para nós mesmos" (Schilder, 1999, p. 11). A imagem corporal social relaciona-se de forma intra e interpessoal, com as emoções e sentimentos do indivíduo consigo, com os outros e com o seu ambiente, com o uso de vestimentas e objetos de adorno. A experiência da nossa imagem corporal e a experiência dos corpos dos outros estão intimamente interligadas, segundo Schilder.

Para Machado (1984), diante de uma câmara não há realidade que permaneça intacta, pois tudo se altera, se arranja e concorre para a ordem ideal do monumento (imagem). Há até quem, agraciado pela natureza, sempre consiga ser fotografado de forma interessante. É a chamada fotogenia, um elemento sem explicação plausível, pois há indivíduos que não têm muita simetria facial, mas saem sempre bem nas fotografias. O mundo assistiu ao nascimento de uma nova profissão, de modelo fotográfico, na qual pessoas treinadas são capazes de se movimentarem e se deslocarem nos espaços com tal eloquência, que "em qualquer momento ou sob qualquer ângulo que a câmara os fixasse, eles dariam uma imagem sempre idealizada e helênica, mas nunca a postura elástica e desairosa de quem é surpreendido por um flagrante" (Machado, 1984, p. 52). Mas nem todos foram contemplados com a fotogenia. E são muitos os que se expõem a uma câmara por bastante tempo, como personalidades em eventos públicos com coberturas foto-jornalísticas. Como controlar rosto e corpo durante tanto tempo?

Os disparos desavisados dos foto-repórteres também podem revelar corpos e rostos deformados. Estas fotos são escolhidas por um editor de jornal e publicadas. Paralisado, tal corpo ou rosto deformado, independentemente do valor noticioso que a ele esteja agregado, quando aparece a ilustrar um facto, vai gerar significados outros.

Ao descrever os modos de se perceber as funções da imagem, o teórico francês Jacques Aumont fala de um modo epistémico, muito específico que é o de estabelecer uma relação do homem com o mundo, cujo valor do vestígio, um valor do idêntico, amplia a função informativa ou referencial (Aumont, 1998, p. 80). Imagens servem para 
ver o mundo e interpretá-lo. Para Aumont, há ainda um modo estético de se perceber as funções da imagem, pois "ao proporcionar ao seu espectador sensações (aisthésis) específicas" (Aumont, 1998, p. 80), a imagem, com suas particularidades, com os seus instrumentos plásticos, é um meio de comunicação que solicita fruição estética, pois estimula no espectador um tipo de expectativa específico e diverso daquele que uma mensagem verbal estimula. A pesquisadora Martine Joly, no seu livro Introdução à análise da imagem, dedica um tópico à associação entre a função referencial e a função estética da imagem, com base no que sustenta Aumont e articulando os dois modos, no que ela considera ser uma imagem intercessão (Joly, 1994, p. 62).

O corpo-imagem fora da normalidade é uma imagem intercessão. Desfigurado, carrega consigo todos os significados da fotografia que procura expressar um facto noticiado, mas carrega ainda a metáfora da máscara que a imprensa coloca nos seus retratados, com a sua estética própria.

\section{DA DESFiguRAÇÃo AO GROTESCO}

A fenomenologia percebe como estética uma complexa relação entre perceção e experiência. O espectador, quando vê uma imagem desfigurada, tem uma experiência transmitida pela imagem, onde o seu olhar recebe um conjunto de significados que vão participar dessa experiência. Existem valores culturais no desfigurado que participam da fruição estética que ele proporciona. Olhos arregalados, nariz disforme, boca aberta. Aliás, a boca, aquela que morde, única estrutura violenta da face, escancarada é sinal de falta de controlo e todo o resto, fora da normalidade, contraria a nossa noção de proporção e de harmonia. Distorcida, a expressão humana perde o equilíbrio, a normalidade, e adentra o campo estético do grotesco. Helmut Jacobs (2014), ao analisar parte da obra do pintor Francisco de La Goya, diz que tudo aquilo que é estranho, deformado, ridículo, fora do regular e do normal, implica o grotesco.

Mikhail Bakhtin diz que o corpo grotesco ultrapassa o próprio corpo, desloca-o num mundo não-corporal. O rosto grotesco, assim como o corpo, está em movimento, não está pronto nem acabado. Para ele, a boca é o centro do rosto grotesco, pois ela é "um abismo corporal escancarado e devorador" (Bakhtin, 1987, p. 277).

É certo que o estilo grotesco faz parte do imaginário humano há muito tempo e foi imortalizado por meio da pintura de forma muito eficiente. Caravaggio e os seus rostos devoradores. Goya e os seus deformados. Munch e o grito. Bosch com as suas caricaturais, obscuras e dantescas personagens... Para Albertino Gonçalves (2002), o corpo grotesco apresenta-se como a antítese do cânone clássico.

$\mathrm{Na}$ pintura do renascimento e do classicismo, os corpos estampam-se como individualidades criteriosamente recortadas do fundo social e natural envolvente. Ora inactivos, ora consagrados a lides nobres, tornam-se cativos, em pose impávida sob ângulo fixo, da lisura bidimensional da tela. (...). Harmónicas, as personagens repousam reificadas em composições banhadas por uma estética da intemporalidade. (Gonçalves, 2002, pp. 126-127) 
Em contrapartida, para o autor, nos quadros grotescos, as figuras apresentam-se sem polimento ou censura, com o que há de mais mundano, com partes baixas do corpo representadas, rostos expressivos e animados, parecem querer saltar da tela.

Muito embora Bakhtin faça uma crítica ao pesquisador alemão Heinrich Schneegans, o primeiro a tentar construir uma teoria do grotesco, em 1894, que teria ignorado questões importantes e ambíguas, ele destaca que Schneegans considera a propriedade essencial do grotesco a caricatura de um fenómeno negativo, tocando a monstruosidade, mas com finalidade última ao satírico (Bakhtin, 1987, p. 272). No imaginário grotesco, o corpo é o cerne, o rebaixamento é o movimento e a modalidade da arte é o riso. Tudo no grotesco é risível, nada existe que não tenha sua parte de ridículo. "O riso torna tudo relativo, arbitrário, transitório, efémero, mesquinho, em suma, vulnerável" (Gonçalves, 2002, p. 128). O riso provocado pelo grotesco, quase sempre, é o riso de zombaria, de escárnio. Ri-se do físico, do ridículo, da anormalidade, mas o que causa o riso, extrapola. Ri-se na verdade sobre o caráter, sobre o psicológico, sobre as facetas espirituais que o corpo sem limites enuncia. Uma correlação entre o físico, a personalidade e o espiritual, explicada por Vladímir Propp (Propp, 1992).

Por este motivo, acreditamos que os processos editoriais da desfiguração também passam por critérios de autoridade moral do retratado. Da mesma forma que a pose se constituiu com um valor social, já estabelecido na ordem do simbólico-cultural, o grotesco assim o é também. A pose configura-se na busca de uma identidade do sujeito, na construção de uma imagem que o represente, num estatuto de perfeição, fechada e acabada. O grotesco, ao contrário, revela o que não deveria, reentrâncias, abismos, orifícios, corpo inacabado, exageros.

Se o grotesco exerce grande fascinação sobre um espectador, pois tem função subversiva e causadora de angústia na deformação corporal, associa-se ainda a legitimidade de um espontâneo publicado em veículos internacionais. O "noema Isso-foi" (Barthes, 1984 , p. 115) é a certeza de que o corpo retratado esteve daquela forma na frente de uma objetiva, e transfere à personagem retratada a responsabilidade de ter o seu próprio corpo desfigurado, ignorando uma escolha posterior, no processo editorial, para justificar a publicação. Essa complexidade é ainda maior se adentrarmos aos universos subjetivos da sociologia do poder, associados às imagens de pessoas da área política. Desta forma, as fotografias do sujeito, em expressões retorcidas criam um discurso do grotesco, voraz e corrosivo, onde o sistema de valores é subvertido, segundo Martins: "avesso à perfeição, à beleza e ao sublime, onde nada se salva" (Martins, 2011, p. 188).

Por outro lado, Gonçalves (2002) diz que a potência grotesca palpita nas veias do social, para sua purga e renovação. Para ele, o extraordinário grotesco coabita e interage no quotidiano como uma manifestação contrária ao poder estabelecido. $\mathrm{O}$ absoluto e a perfeição são ilusões estéreis e perigosas, que importa relativizar e retemperar e, para Gonçalves, o discurso do grotesco tem essa função, com os inacabados, mutilados, disformes e incompletos. Assim as categorias dominantes desmoronam-se. Os discursos oficiais perdem força e sentido, na turbulência grotesca. O autor considera que no universo grotesco, "os principais protagonistas tendem a ser sujeitos coletivos hiperbólicos 
e exorbitantes" (Gonçalves, 2002, p. 119). Por este motivo, o espontâneo grotesco, no fotojornalismo, é um fenómeno que parece atingir os políticos do mundo inteiro.

Gonçalves retoma a ambivalência de Bakhtin, para falar na força renovadora do grotesco, pois degradar, ligar-se ao baixo corporal é também ligar-se ao que há de mais humano, provocando rupturas e renascimento, ao redimir pela poluição. Gonçalves (2002) atenta para um grotesco cada vez mais presente, seja pela fotografia, pela cirurgia plástica, pelos efeitos ciborgues da tecnologia de ponta utilizada nos amputados, na medicina regenerativa. Para o autor, o grotesco está muito presente na nossa sociedade e parece ser um fenómeno em fase de expansão, quando se observa o cinema, a publicidade, os videojogos, os programas de reality show na televisão. Sem dúvida podemos acrescentar o fotojornalismo a tal lista.

Há na fotografia grotesca, publicada nos veículos jornalísticos importantes, de grande divulgação nacional e internacional, uma intenção caricatural e faz-se de um instrumento de informação uma arma do riso que ridiculariza a personalidade fotografada. Será o fotojornalismo uma forma de desautorizar ou de humanizar poderosos que se acham acima dos mortais? A fotografia do grotesco, que transforma o sujeito em caricatura de si mesmo, que provoca a distorção das formas e, portanto, do estabelecido, consegue retirar poder, desautorizar políticos e pessoas influentes? Estar sob a mira da câmara é estar sempre disponível à transformação grotesca?

O estudo do poder, segundo Anthony Giddens (2008, p. 424), é de extrema importância para a Sociologia, pois o poder está presente em todas as relações sociais. Ele conceitua poder como a capacidade que indivíduos ou grupos possuem, de fazer valer os seus próprios interesses, mesmo quando outros se opõem. A imprensa, quando escolhe uma fotografia com uma determinada pose ou com uma não-pose, está de alguma forma, a dar ou retirar poder ao sujeito fotografado, pela figuração de corpo em que ele se encontra. Também ela, a imprensa, ao usar o espontâneo como discurso, como técnica, sendo o espontâneo uma prática, possível a todos os foto-repórteres que tem câmaras capazes (tecnologia-poder), impõe sobre o retratado uma situação de transfiguração. Também o processo de escolha do editor, ao ter um número determinado de fotografias de uma personagem, mas ao escolher a grotesca, exerce um poder sobre o corpo do retratado e sua imagem social.

\section{CONSIDERAÇÕES FINAIS}

Toda e qualquer imagem nos média é um resultado de um processo discursivo, que deriva de escolhas de fotógrafos, editores, designers que, ao divulgar uma fotografia num jornal, revista ou site, escolhem elementos de composição, títulos e legendas que a acompanham, tonalidades, contrastes, fazem cortes. No caso de um sujeito fotografado, escolhem inclusive as suas figurações de corpo, os suas expressões e gestos.

Os processos digitais, com os cartões de memória e as câmaras automáticas, facilitaram e fortaleceram o discurso do espontâneo. O fotojornalismo abandonou o instante decisivo, e sustenta-se em recursos que produzem espontâneos sequenciais, em que 
o corpo do sujeito retratado pode ser usado contra ele mesmo. Muitas personagens são assim retratadas. Todos os veículos publicam fotos nesse estilo. É um modus operandi. Um sistema simbólico estabelecido (Bourdieu, 1989, p. 16).

Pierre Bourdieu escreveu o quanto é importante descobrir onde o poder se deixa ver menos. Não que ele seja menor. Há tipos de poderes que parecem nem existir ou nem exercer pressão sobre outras coisas. Esse discurso do espontâneo atua com esse tipo de poder. É um poder ignorado. Um poder simbólico, pouco reconhecido, quase invisível, "o qual só pode ser exercido com a cumplicidade daqueles que não querem saber que lhe estão sujeitos ou mesmo que o exercem" (Bourdieu, 1989, p. 8).

O fotojornalismo finge que não tem o controlo sobre o corpo do outro. Quem trabalha com uma câmara profissional numa cobertura jornalística sabe o quanto a imagem do sujeito está sob seu domínio. O espontâneo atual, então, não é uma realidade mas uma simulação, um discurso que se mantém real, pois existe na teoria sustentado por uma tradição. No entanto, hoje ocorre sem a perícia e o talento do fotógrafo, acontecendo ao invés graças à viabilidade proporcionada pela tecnologia. Diante de todas as possibilidades de divulgação da imagem social do outro, geradas em obturações contínuas, o editor escolhe muitas vezes um gesto não concretizado. $O$ sujeito não parou a sua fala a meio, fez uma cara distorcida e continuou a falar.

Vilém Flusser compara um fotógrafo a um caçador, operando uma arma (câmara) com um gatilho (disparador), cuja intenção é capturar uma imagem. Esta imagem está categorizada em regiões culturais na hora do disparo. O fotógrafo não fotografa processos, como no cinema, onde há movimento e continuidade. O fotógrafo paralisa processos, pois escolhe uma cena, retira a cena do contexto:

para fotografar, o fotógrafo precisa, antes de mais nada, conceber sua intenção estética, política, etc., porque necessita saber o que está fazendo ao manipular o lado output do aparelho. A manipulação do aparelho é um gesto técnico, isto é, um gesto que articula conceitos, antes de poder transcodificá-la em imagens. Em fotografia não pode haver ingenuidade. (...) Qualquer intenção estética, política ou epistemológica deve, necessariamente, passar pelo crivo da conceptualização antes de resultar em imagem. $\mathrm{O}$ aparelho foi programado para isso. Fotografias são imagens de conceitos, são conceitos transcodificados em cenas. (Flusser, 1998, p. 52)

Assim, quando um foto-repórter congela uma imagem, seja ela uma pose, ou um espontâneo, uma não-pose ou uma desfiguração, sabe bem por que o faz e não depende do fotografado a cena que será congelada. Mas pela dimensão de construção social da realidade, em consonância com a mesma dimensão que recebe o jornalismo, uma foto publicada na imprensa pode gerar subjetividades outras.

Assim, perpetuar uma prática, sob o discurso de um espontâneo que já não se justifica como técnica, é talvez dar uma valoração às imagens grotescas, naturalizando-as como discursos do sujeito fotografado e não como processos discursivos editoriais. A imagem social de um sujeito retratado, caricaturado, associado ao grotesco, ganha um novo sentido no imaginário social. 


\section{REFERÊNCIAS BIBLIOGRÁFICAS}

Aumont, J. (1998). A imagem. Campinas, São Paulo: Papirus.

Bakhtin, M. (1987). A cultura popular na idade média e no renascimento: o contexto de François Rabelais. São Paulo: Hucitec.

Barrocas, A. (2014). Sais de sangue - o corpo fotografado: teoria e prática da fotografia em Portugal. Tese de Doutoramento, Universidade de Lisboa, Lisboa, Portugal. Retirado de http://repositorio.ul.pt/ handle/10451/15632

Barthes, R. (1984). A câmara clara. Rio de Janeiro: Nova Fronteira.

Benjamin, W. (1987). Magia e técnica, arte e política: ensaios sobre literatura e história da cultura. São Paulo: Brasiliense.

Bourdieu, P. (1989). O poder simbólico. Lisboa: Difel.

Cruz, M. T. (2007). Espaço, média e experiência. Na era do espaço virtual e do tempo real. Comunicação e Sociedade, 12, 23-38. doi: 10.17231/comsoc.12(2007).1094

Cunha, T. C. (2009). Argumentação e metáfora no discurso político. Comunicação e Sociedade, 16, 19-25. doi: 10.17231/comsoc.16(2009).1027

Duelo de aperto de mão rouba a cena em encontro Trump-Trudeau (2017, 14 de fevereiro). Veja. Retirado de http:// veja.abril.com.br/blog/headlines/duelo-de-aperto-de-maos-rouba-a-cena-em-encontro-trump-trudeau/

Eco, U. (1985). La guerre du faux. Paris: Editions Grasset \& Fasquelle.

Fabris, A. (2004). A captação do movimento: do instantâneo ao fotodinamismo. ARS, 7, 51-77. doi: 10.1590/ S1678-53202004000400005

Flusser, V. (1998). Ensaio sobre a fotografia: para uma filosofia da técnica. Lisboa: Relógio d'água.

Freund, G. (1983). La fotografía como documento social. Barcelona: Grafos S.A.

Giddens, A. (2008). Sociologia. Lisboa: Fundação Calouste Gulbenkian.

Gonçalves, A. (2002). O delírio da disformidade. O corpo no imaginário grotesco. Comunicação e Sociedade, 4, 117-130. doi: 10.17231/comsoc.4(2002).1286

Gradim, A. (2007). O que pedem as imagens? Comunicação e Sociedade, 12, 189-200. doi: 10.17231/ comsoc.12(2007).1104

Horta, N. B. (2015). O meme como linguagem da internet: uma perspectiva semiótica. Dissertação de mestrado, UNB, Brasília, Portugal. Retirado de http://repositorio.unb.br/bitstream/10482/18420/1/2015_ NataliaBotelhoHorta.pdf

Hunt, E. (2016, 17 de dezembro). What is fake News? How to spot it end what you can do to stop it. The Gardian. Retirado de https://www.theguardian.com/media/2016/dec/18/what-is-fake-news-pizzagate

Jacobs, H. C. (2014). Lo grotesco como programa de la ilustrácion em el Capricho 4 de Francisco de Goya. Acta/Artis. Estudis d'Arts Moderns, 2, 69-95.

Joly, M. (1994). Introdução à análise da imagem. Lisboa: Edições 70.

Machado, A. (1984). A ilusão especular. São Paulo: Brasiliense/Funarte. 
Máquina fotográfica Leica vendida por valor recorde (2010, 5 de dezembro). TVI 24. Retirado de http://www. tvi24.iol.pt/economiamedia-e-tecnologia/fotografia-maquina-fotografica-leica-leilao-dinheiro-agenciafinanceira/1215461-2974.html

Martins, M. L. (2011). Crise no Castelo da Cultura. Coimbra: Grácio Editor.

Mauad, A. M. (2008). O Jânio que ficou na retina. Revista de História. Rio de Janeiro: Biblioteca Nacional. Retirado de http://www.revistadehistoria.com.br/secao/perspectiva/o-janio-que-ficou-na-retina

Pinto, S. \& Martins, M. L. (2017). Lógicas de vinculação na arte. Comunicação e Sociedade, 31, 253-269. doi: $10.17231 /$ comsoc.31 (2017).2616

Propp, V. (1992). Comicidade e riso. São Paulo: Ática.

Schilder, P. F. (1999). The image and appearance of the human body. Studies in the constructive energies of the psyche. Londres: Routledge.

Sontag, S. (2004). Sobre fotografia. São Paulo: Companhia das Letras.

Sousa, J. P. (1998). Uma história crítica do fotojornalismo ocidental. Porto: Universidade Fernando Pessoa.

Sousa, J. P. (2001). Elementos de Jornalismo Impresso. Porto: Universidade Fernando Pessoa.

Sousa, J. P. (2002). Fotojornalismo: uma introdução à história, às técnicas, à linguagem. Porto: Universidade do Porto.

The Guardian (2017, 14 de fevereiro). Donald Trump's strange handshake style and how Justin Trudeau beat it [vídeo]. Retirado de https://www.theguardian.com/us-news/video/2017/feb/14/ donald-trumps-strange-handshake-style-and-how-justin-trudeau-beat-it-video-explainer

\section{WEBGRAFIA}

All world wars. Crimean War Photographs by Rober Fenton, March-June 1855. Retirado de http://www. allworldwars.com/Crimean-War-Photographs-by-Roger-Fenton-1855.html.

Esso. Ano de 1962, Prémio Principal. Retirado de http://www.premioexxonmobil.com.br/site/premio_ principal/index.aspx?year $=1962$

Magnum Photos. Overview. Retirado de https://www.magnumphotos.com/about\%2omagnum/overview/.

Magnum Photos. Henri-Cartier Bresson. Retirado de https://www.magnumphotos.com/photographer/ henri-cartier-bresson/.

Nikon, History. Chronicles. Vol. 4. Nikon F2. Retirado de http://imaging.nikon.com/history/chronicle/ rhnco4f2-e/index.htm.

Phantom. Phantom Camera Products. Ultrahigh-Speed Cameras. Retirado de https://www.phantomhighspeed. com/Products/Ultrahigh-Speed-Cameras.

SanDisc. History of the SanDisk Brand. Retirado de https://www.sandisk.com/about/company/history. 


\section{NOTAS BIOGRÁFICAS}

Alene Lins é estudante de doutoramento no Programa Doutoral em Ciências da Comunicação da Universidade do Minho e investigadora do CECS-UM. Professora da Universidade Federal do Recôncavo da Bahia, ensina fotografia e teoria da imagem. Trabalhou como jornalista, fotógrafa e repórter de televisão no Brasil. Seus interesses de pesquisa concentram-se nas mudanças na imagem após o processo digital.

E-mail: aleneufrb@gmail.com

Rua Dr. José Vilaça, 75, 6A, São Lázaro - 4705-094 Braga, portugal

Madalena Oliveira é Professora Associada no Instituto de Ciências Sociais e membro do Centro de Estudos de Comunicação e Sociedade da Universidade do Minho. Doutora em Ciências da Comunicação, ensina semiótica, comunicação e línguas, jornalismo e som e jornalismo especializado. Sua pesquisa concentra-se no média rádio como linguagem. É vice-presidente da Associação Portuguesa de Ciências da Comunicação (Sopcom), coordenadora do Grupo de Trabalho de Rádio e Som da Sopcom e presidente da Seção de Pesquisa de Rádio da Ecrea.

E-mail: madalena.oliveira@ics.uminho.pt

Instituto de Ciências Sociais - Universidade do Minho - Campus de Gualtar 4710-057 Braga, Portugal

Luís António Santos é Professor Associado no Instituto de Ciências Sociais e membro do Centro de Estudos de Comunicação e Sociedade da Universidade do Minho. Doutor em Ciências da Comunicação e Diretor Adjunto do Centro de Pesquisa de Comunicação e Sociedade. Ele trabalhou como jornalista por mais de uma década, inclusive como correspondente de Londres para o Diário de Notícias, durante seu tempo na BBC. Seus interesses de pesquisa concentram-se em mudanças no campo do jornalismo, rádio e produção de som. Ele é comentarista e produz regularmente crônicas para a Rádio Renascença.

E-mail: Isantos@ics.uminho.pt

Instituto de Ciências Sociais - Universidade do Minho - Campus de Gualtar 4710-057 Braga, Portugal

* Submetido: 16-08-2017

* Aceite: 15-11-2017 